\title{
CONTEXTUALIZAÇÃO DO ENSINO DA QUÍMICA ATRAVÉS DE PLATAFORMAS DIGITAIS E REDES SOCIAIS: PROJETO ORBITANDO CIÊNCIA
}

Paola Cristina Ribeiro

\section{Introdução}

No mundo todo estamos cada vez mais conectados por meio da internet, seu acesso tem feito parte da rotina dos brasileiros, como mostra um estudo do IBGE (2018) apontando que entre os anos de 2016 e 2017 houve um aumento de acesso à internet de 4,8\% nas áreas urbanas e 6,4\% nas áreas rurais, esse novo cenário torna propicio a introdução de TICs (tecnologias da comunicação e informação) no ensino, bem como estender o conhecimento cientifico a toda comunidade no geral de forma mais clara e objetiva.

A facilidade de acesso por meio de telefone móvel celular tem tornado o dispositivo como preferência de utilização dos brasileiros, segundo IBGE (2018) houve um aumento de $2,4 \%$ de pessoas que acessaram a internet por meio do celular, enquanto a utilização da internet 
por meio de microcomputador caiu $7,1 \%$, seguido do tablete que também teve uma queda de $2,1 \%$, como pode ser visualizado na figura 1.

Figura1: Pessoas que acessaram a internet, segundo o equipamento utilizado.

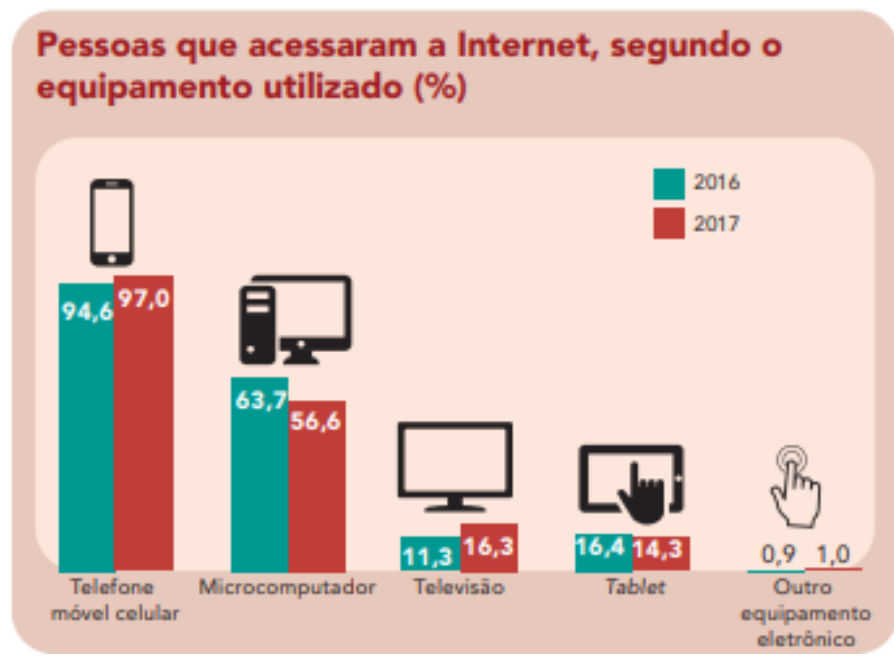

Fonte: IBGE, 2018

Quando se trata de finalidade de acesso a internet o maior aumento percentual foi para pessoas que utilizam a rede para conversar por chamada de voz ou vídeo $(9,4 \%)$, seguido pela preferência em assistir a vídeos, inclusive programas, séries e filmes, com um aumento de $5,4 \%$, apontando para uma curva ascendente do brasileiro por procura de conteúdos por vídeos. Junto com todo esse aumento de busca por conteúdos visuais por meio da internet, alguns estudos também 
apontaram para a procura de conteúdos curriculares em redes sociais, como um estudo realizado no México em 2013 apontando que em um grupo de alunos registrados em uma disciplina de química orgânica II, $80 \%$ deles afirmaram pertencer a um grupo de estudos privado no Facebook relacionados à matéria, e cerca de $90 \%$ disse dispor de ferramentas tecnológicas para consultas e dúvidas sobre a matéria. Devido à facilidade e acessibilidade a comunicação virtual vem abrindo caminhos para novas formas de ensino, aprendizagem e divulgação científica. (MANSILLA et al,2013)

De acordo com Litwin (2005) a tecnologia vem sendo utilizada pela educação desde a década de 50, de uma forma variada, passando pelos retroprojetores até as aulas virtuais de educação à distância tão difundidas hoje em dia. Nas primeiras décadas a tecnologia se remetia somente a teorias computacionais, sendo que a didática abrangia uma grande quantidade de disciplinas como psicologia, sociologia, história da educação e políticas educativas, naquela época era somente uma ferramenta para ajudar a solucionar problemas. Com a inovação das últimas décadas e a incorporação de novas tecnologias na educação o ensino virtual em múltiplas ocasiões não parece demonstrar diferença em relação ao estudo presencial.

Em Madri na Espanha aplicaram atividades práticas por meio da internet em um curso de engenharias 
da computação e automação, em um controle de sistema de três tanques e a programação de um robô, e de acordo com os resultados obtidos puderam contemplar o elevado grau de satisfação dos alunos que utilizaram o estudo virtual do projeto denominado AutomatL@bs, por meio de uma pesquisa que pode ser observada na figura 2 . (VARGAS et al,2010)

Figura 2: Resultado de evolução da pesquisa de avalição do experimento no período de 2007 a 2008.

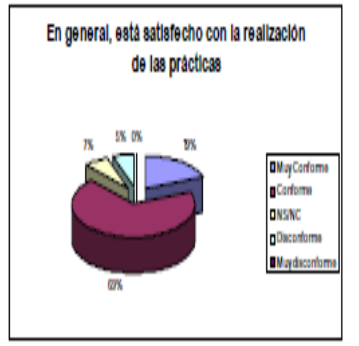

(a)

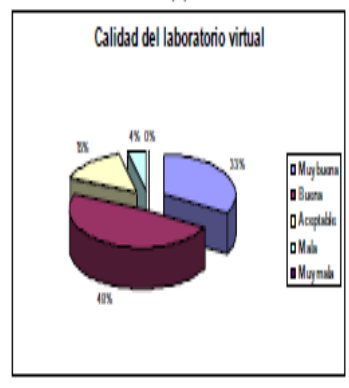

(d)

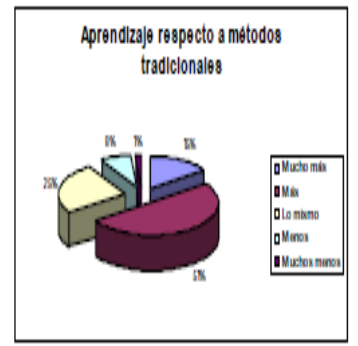

(b)

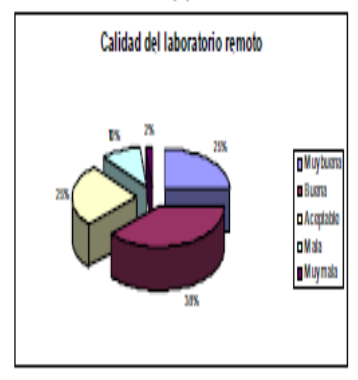

(e)

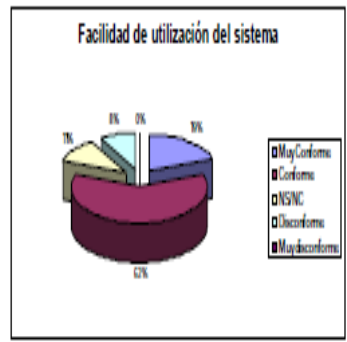

(c)

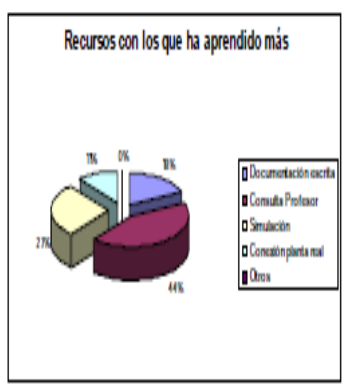

(f)

Fonte: VARGAS et al, 2010

A química possui um papel social muito importante, podendo se levar em consideração outras esferas 
do conhecimento, designando uma nova forma de ensino aprendizagem, opondo-se ao ensino centrado. Novas propostas como demonstrado por Ferreira et al (2011), incluem textos de divulgação cientifica (TDCs) para alunos do ensino superior, proporcionando uma elaboração de perguntas com diferentes objetivos, levantando diversas questões e permitindo abordagens diversas. De fato, as expressões transmitidas pelos estudantes apontaram para o desenvolvimento de habilidades como leitura e interpretação de TDCs, bem como aperfeiçoamento da comunicação oral e o processo de construção dos TDCs.

O projeto Orbitando Ciência é um canal criado nas redes sociais que busca o conhecimento científico e a química em artigos publicado na área, bem como em livros e transforma esse conhecimento em curiosidades por meio de uma linguagem mais lúdica e objetiva, tornando o aprendizado mais claro a qualquer pessoa leiga no assunto. Entre outras ferramentas o projeto orbitando ciência leva em consideração à química e o ambiente como um todo, observando desde pequenos acontecimentos na vida de cada indivíduo, permitindo que ele se expresse e entenda o conteúdo de acordo com sua própria experiência e realidade. Assim como demonstrado por Ferreira et al (2011) a abordagem de textos científicos leva a uma maior percepção de vida, o orbitando ciência busca levar isso as pessoas que não têm contato com os TDCs, de uma forma mais simples e uma abordagem mais lúdica, utilizando a tecnologia como transmissão de conhecimen- 
to, pois é considerado um dos principais meios de pesquisas e acesso dos indivíduos do mundo atual.

Essa abordagem temática do ensino de química e ciências já vem sendo proposta por outros autores, como Fernandes et al (2015) propôs a utilização de modelos temáticos virtuais por professores em salas de aula, tal modelo leva em consideração o modo da pedagogia ativa, como a utilização de TICs no ensino de ciências.

O projeto Orbitando Ciência tem como principal objetivo promover o conhecimento científico por meio das redes sociais, abrangendo um público mais amplo, com uma linguagem acessível a estudantes e pessoas que não tiveram acesso a formação completa na escola. Tais plataformas permitem uma integração entre si, possibilitando a aprendizagem de formas diferentes

\section{Metodologia}

Por ser realizada por meio da internet o projeto possibilitou uma maior abrangência da área de estudo, chegando a pessoas de todas as regiões do Brasil.

Os assuntos a serem abordados foram selecionados previamente por uma professora de química, ao escolher o assunto foram realizadas pesquisas de artigos que abordavam o tema principal do assunto, feito a curadoria 
de conteúdo isso foi interpretado e transcrito para um texto mais sucinto e objetivo, buscando abranger o publico alvo que foram estudantes e adultos leigos no ensino de química.

Foram gravados vídeos explicando cada assunto, também foram utilizados imagens e textos, os quais foram editados e formatados, abordando o tema principal, proporcionando uma forma mais lúdica e chamativa para informação científica. A contextualização do ensino da química em forma de vídeos e imagens foi realizada em plataformas de redes sociais, para divulgação de vídeos foi utilizada a plataforma do YouTube, e para divulgação de imagens e textos de curiosidades relacionados a química e divulgação científica foi utilizada a plataforma do Instagram.

\section{Resultados e discussão}

O projeto Orbitando Ciência utilizou de duas principais plataformas de entretenimento para divulgação de textos de divulgação científica, buscando abranger pessoas de todas as faixas etárias através de uma linguagem simples. Foram utilizados assuntos de objetos tecnológicos, utensílios indispensáveis em nossas vidas, que muitos não sabiam de onde surgiram, quais pesquisas foram feitas para chegar ao que temos hoje, quais materiais foram utilizados para fabricação de tais objetos. Todos 
esses assuntos foram separados por temas e abordados em forma de imagem ou vídeos.

Abordagem por meio de imagens

O tema foi inserido por meio da rede social Instagram, com as seguintes temáticas: curiosidades, perguntas, notícias, humor e educação ambiental, todos relacionados à química e a ciência. Na temática curiosidade foram abordados conteúdos históricos, mostrando grandes descobertas feitas pela ciência ao longo dos anos, podendo abordar assuntos como o papel da química para o avanço tecnológico que usufruímos no mundo atual e suas composições. A química pode nos demonstrar a composição das coisas, permitindo observar a complexidade de tudo que nos cerca, como na figura 3 .

Figura 3: A química das coisas, temática curiosidades.

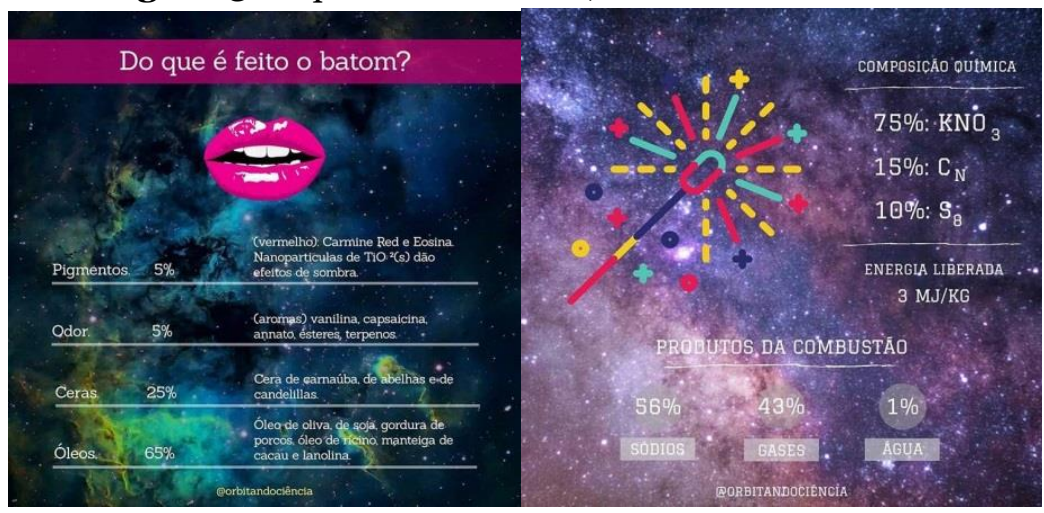

Fonte: RIBEIRO, 2020 
Fatos históricos também podem ser abordados no contexto da química, como episódios de poluição excessiva, onde o primeiro episódio de poluição excessiva é datado de 1930 no vale de Meuse na Bélgica, alguns anos depois no ano de 1952 em Londres, devido ao excesso da queima de carvão agravado por uma inversão térmica, tal acontecimento ocasionou um aumento de quatro mil óbitos em relação à média esperada pelo período, esse excesso de mortes levou a criação de estudos para controle da emissão de poluentes do ar. Nesse contexto trazendo para o momento presente, ainda nos deparamos com episódios de poluição excessiva, e vários estudos vêm demonstrando seus efeitos na saúde humana. Por meio da divulgação de acontecimentos passados podemos obter aprendizados para não os repetir. Levar em consideração questionamentos sobre temas como a poluição do ar, trazendo evidências científicas, demonstrando como esquecemos fatos importantes e a necessidade de se discutir a poluição envolvendo áreas multidisciplinares como saúde pública, química, meio ambiente entre outras. (RIBEIRO et al,2019) 
Figura 4: Fatos históricos comparando os primeiros episódios de poluição excessiva e os atuais.

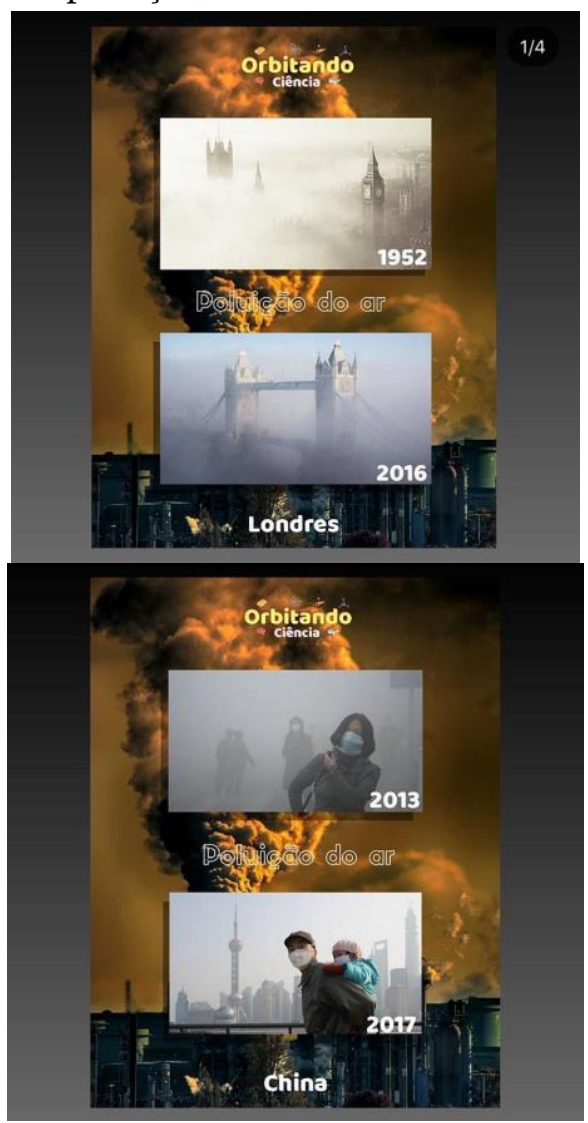

Fonte: RIBEIRO, 2020

As notícias também podem vir de acontecimentos novos e avanços da ciência como a descoberta da fosfina ( $\mathrm{PH}_{3}$ ) nas nuvens de Vênus, tal estudo encontrou o $\mathrm{PH}_{3}$ nas nuvens do planeta vizinho, levando a questionamentos sobre a presença de vida venusiana, tal hipótese ainda 
precisa ser confirmada, porém abre caminho para discussões no ensino como a formação do $\mathrm{PH}_{3}$, como ele é formado, a atmosfera hiperácida de Vênus, entre outros saberes. (GREAVES et al, 2020)

Nos tempos atuais com a tecnologia na palma de nossas mãos, nos vemos cada vez mais procurando por espaço de armazenamento de dados e velocidade para abrir um simples aplicativo, mas ao olharmos para fatos históricos percebemos que a missão Apollo 11 foi para lua utilizando um computador de apenas $2 \mathrm{~kb}$, esse ocorrido nos permite fazer uma reflexão sobre como estamos utilizando a tecnologia que nos está disponível?

Vários caminhos de aprendizagem da química vêm sendo estudados, como utilizar o teatro para o ensino da química com peças que abordam conteúdo científico, no Brasil existem alguns grupos que podem ser citados como: Ouroboros, Fanáticos da Química, Tubo de Ensaio, LetraFísicoQuímic, Química em Cena, Show da Química, Alquimia, dentre outros. Outro estudo também apontou a utilização de séries de TV como The 100 e Breaking Bad para discussão em sala de aula, enfatizando que as séries estão no cotidiano dos jovens e podem atingir um contexto mais abrangente fazendo parte também do cotidiano dentro da escola, ressaltando ainda que os professores devem estar por dentro do mundo de seus alunos precisando se renovar para proporcionar no seu aluno o interesse. Desta forma uma abordagem mais lú- 
dica pode ser obtida por meio de memes (Figura 5), muito utilizado nas redes sociais, onde situações rotineiras de sala de aula e laboratório podem ser contextualizadas para o ambiente externo. (SOUZA e LEITE, 2018; VENTURA et al, 2018)

Figura 5: A química no humor por meio de memes.

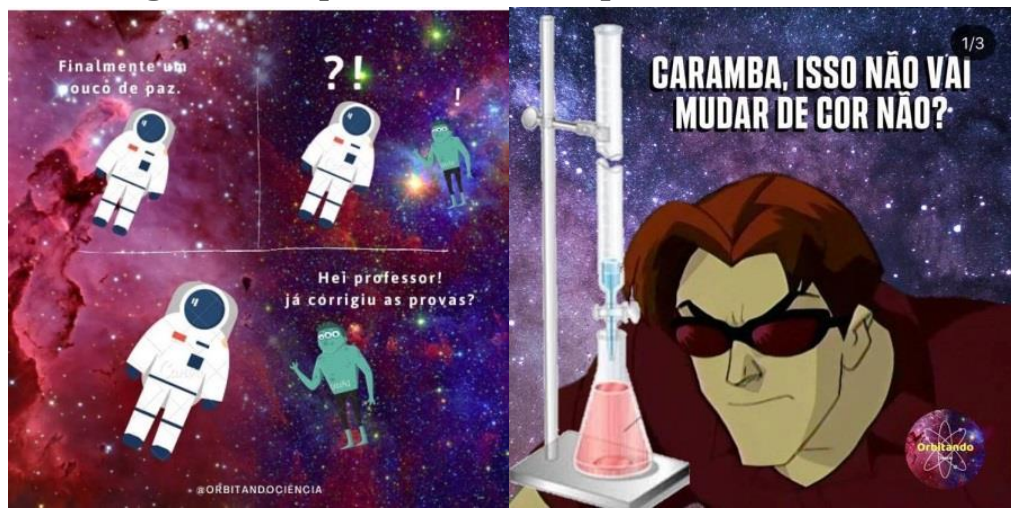

Fonte: RIBEIRO, 2020

Por meio de perguntas em forma de QUIZ (Figura 6) e roupagem de game, exercícios envolvendo áreas de química orgânica, química geral, inorgânica entre outras podem ser abordadas como forma de desafios. Notícias de novas descobertas e acontecimentos científicos traduzem a importância da ciência e uma vivência do espectador nesse mundo acadêmico. 
Figura 6: Ensino da química através de perguntas em formato de quiz e game.

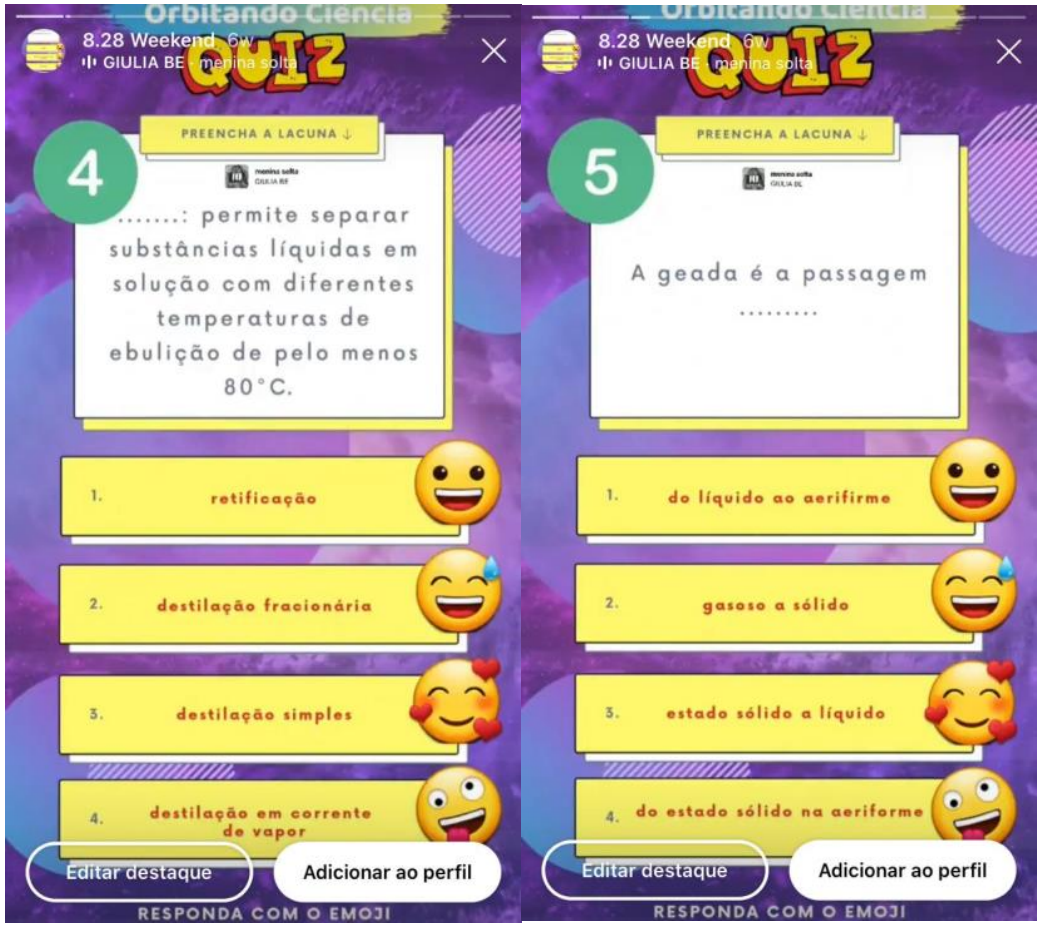

Fonte: RIBEIRO, 2020

Inserir a educação ambiental por meio de conscientização e explicação de fatos ambientais, a nova complexidade planetária e aprendizagem social vêm sendo discutida amplamente e abordada em diferentes instituições do ensino médio, regular e do ensino de para Jovens e adultos. (MIRANDA et al, 2018) 
No ano de 2014 um estudo que levava em consideração instituições e práticas especializadas de produção de conhecimento e o sistema educativo de governo, comparou seis países latino-americanos, dentre Argentina, Brasil, Chile, México, Paraguai e Uruguai, apontando que o México e o Brasil se sobressaiam em relação aos demais países, em relação à configuração de um campo de investigação educativa integrado a nível nacional e níveis significativos de produção acadêmica. Retomando a importância da integralização dos saberes. (PALAMIDESSI,2014)

O objetivo de levar a reflexões que permitam um novo olhar da sociedade para questões ambientais pode ser atingido abordando conteúdos como arborização das ruas, o excesso e descarte do lixo, poluição atmosférica entre outros. Tal abordagem pode ser exemplificada na figura 7 , onde o objetivo foi apontar os benefícios e as desvantagens da arborização das ruas, motivando a discussão do calor, amenização de temperatura, impermeabilização do solo entre outras questões que envolvem diversas áreas do conhecimento.

Todo o contexto da arborização das ruas foi retirado de um artigo onde foram analisadas três ruas da cidade de Curitiba na região sul do Brasil, medindo a temperatura do ar nos trechos arborizados e sem arborização por meio de aparelhos específicos, considerando também humidade relativa do ar; ponto de orvalho, pressão at- 
mosférica e altitude. Tudo isso permitiu que concluíssem que a arborização das ruas proporciona um microclima urbano mais ameno durante a maior parte do dia afetando também a humidade do ar que se manteve maior nas ruas arborizadas. (MARTINI et al,2013)

Figura 7: Exemplificação de educação ambiental com o tema O porquê de arborizar ruas.
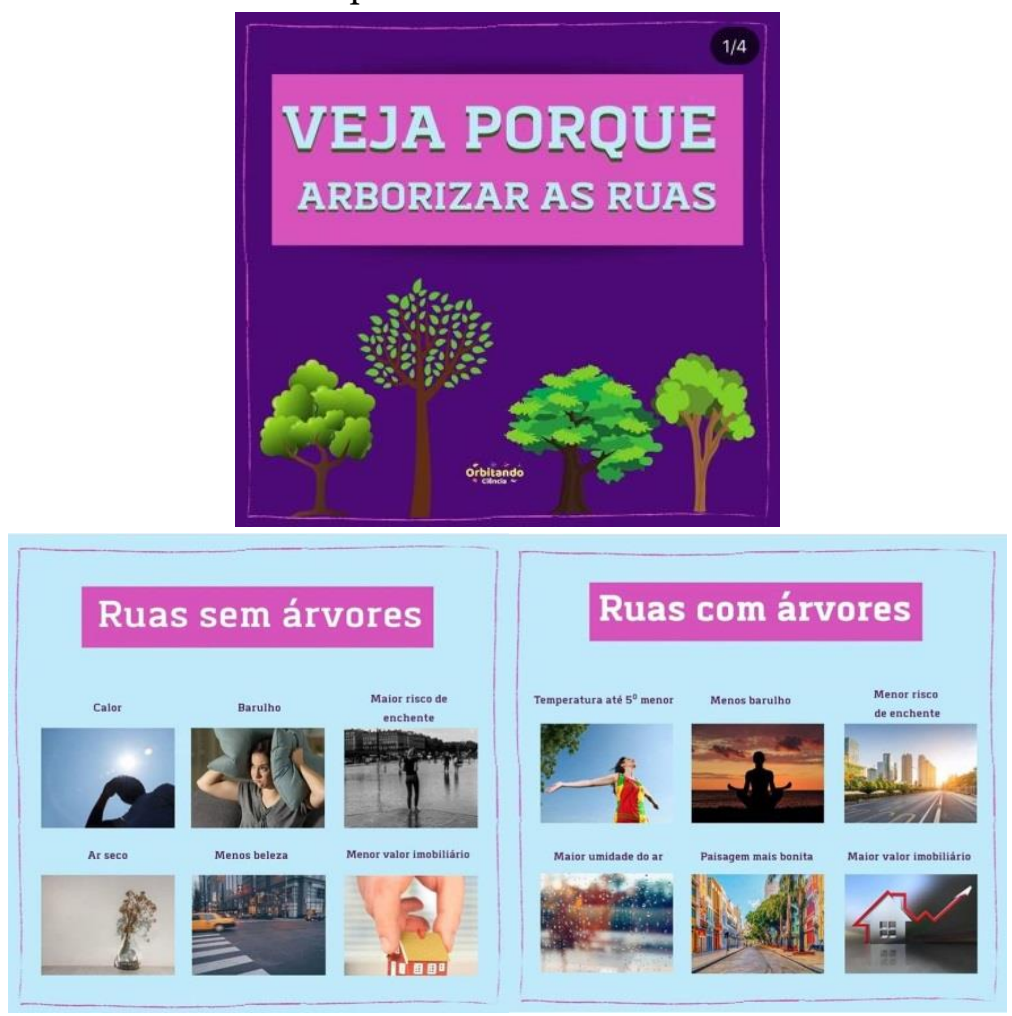

Fonte: RIBEIRO, 2020 
Por meio da plataforma YouTube, utilizando vídeos foi feita uma abordagem mais completa de temas comuns explicando-os com base em artigos científicos, como também experiências que podem ser replicadas em casa. Como demonstrado em um estudo feito pelo IBGE a busca de conhecimento e informações no formato de vídeo vem crescendo ao longo dos anos, ressaltando a importância de inserir conteúdos de cunho científico nessas plataformas. (IBGE,2018)

Abordagem por meio de vídeos

Os vídeos foram separados em dois temas diferentes, o primeiro abordou a explicação de fenômenos naturais e antropológicos, demonstrando o papel da química em tais acontecimentos, bem como a forma e ordem que eles ocorrem. Já o segundo tema abordou experiências simples que podem ser realizadas em casa com objetos do dia a dia, tal contexto permite a exploração do conhecimento por meio do protagonismo do espectador, permitindo ir além da experiência visual, vislumbrando outros sentidos. Tal forma de aprendizado já foi apresentada por Vargas et al (2010) onde foram aplicadas atividades práticas por meio da internet.

A química protagonizou os noticiários mundiais em 2020, um dos temas apresentados foi a explosão ocorrida no Líbano, onde o Nitrato de amônio armazena- 
do de forma inadequada ocasionou um grave acidente, tal acontecimento levou a procurar por informações sobre a substância, abrindo uma porta de comunicação para mostrar a importância da química para o mundo. Nesse caso foi abordada a composição química do Nitrato de amônio e onde pode ser utilizado, além dos perigos de se utilizar de forma inadequada (Figura 8).

Figura 8: Vídeo com o tema da explosão de Beirute.

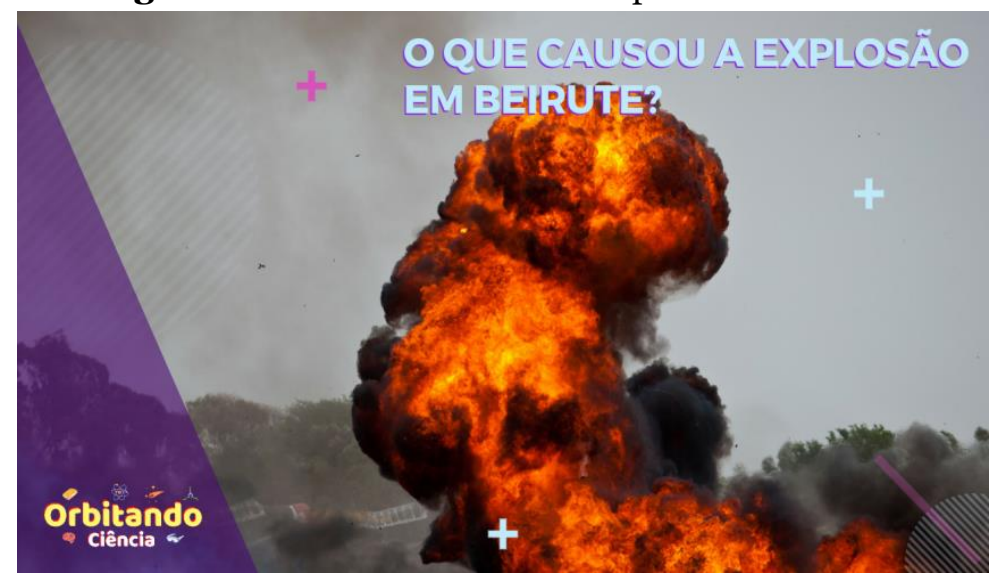

Fonte: RIBEIRO, 2020

O ano de 2020 está sendo repleto de acontecimentos, outro fator que parou o mundo foi a Pandemia do COVID -19, uma verdadeira corrida contra o tempo para uma solução contra um vírus desconhecido, na espera por vacinas, pesquisadores buscaram outras soluções para conviver melhor em meio ao vírus, uma das pesquisas realizadas foi à criação do tecido anti-covid (Figura 9), onde a presença de íons de prata demonstrou inativar 
grande parte dos vírus no tecido, a busca por novas tecnologias e aprimoramento das existentes ganhou lugar de destaque nos noticiários. A busca por informações referentes a produção de vacina e álcool em gel nas redes sociais fomentou discussões e opiniões diversas, tudo isso corrobora ao fato de que a divulgação científica precisa ser feita, os fatos precisam ser divulgados para que a sociedade conheça e perceba a importância da ciência no desenvolvimento do país e na vida das pessoas. (FAPESP,2020)

Figura 9: Vídeo explicando o tecido anti covid

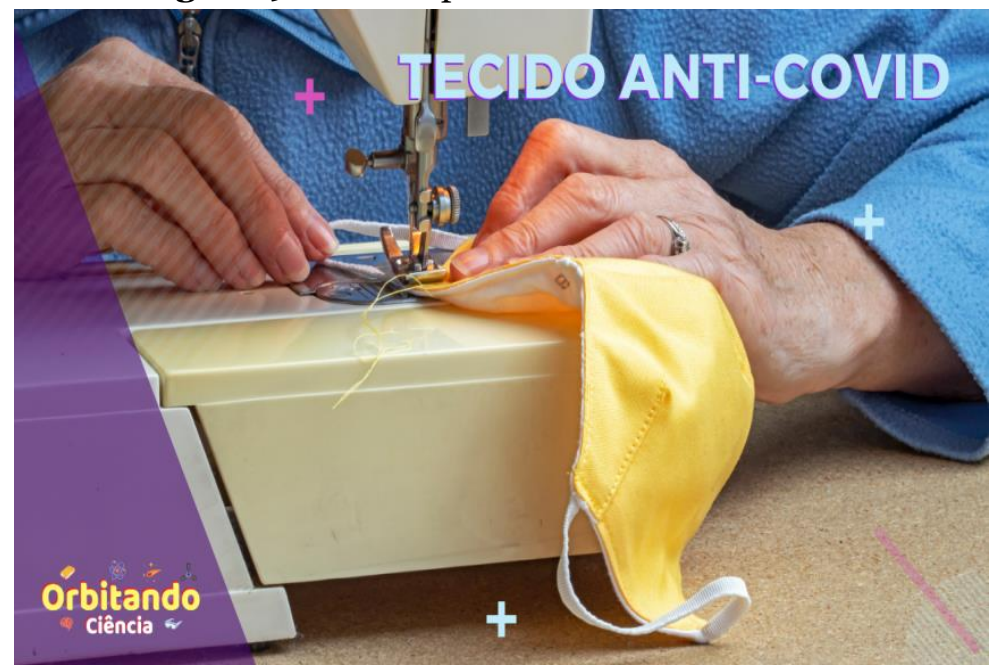

Fonte: RIBEIRO, 2020

No entanto não precisamos de eventos catastróficos para demonstrar a importância e presença da química, basta olhar para dentro de nossas casas, como exem- 
plo o gás de cozinha GLP (gás liquefeito do petróleo), seguindo essa linha de pensamento explicamos do que é composto o GLP, composição química e de onde é extraído. E se observarmos melhor verá a química dentro de nós mesmos, como exemplo a química do nosso cérebro, tais substâncias são responsáveis por sensações específicas e respostas a determinados estímulos, na figura 10 pode ser visto o tema abordado, o qual falou sobre a dopamina, seus efeitos em nosso organismo além de pesquisas realizadas associando a falta ou o excesso da substância a algumas doenças como Parkinson e Esquizofrenia.

Figura 10: Vídeos abordando temas do dia a dia.

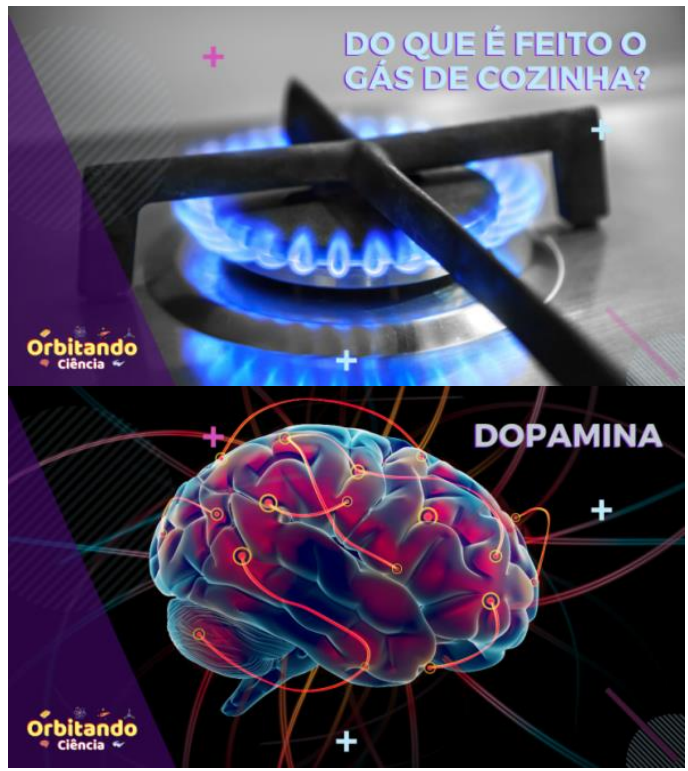

Fonte: RIBEIRO, 2020 
Além de abordar e explicar acontecimentos, o projeto também tem uma sessão com experiências que pode ser replicada em casa, o aprendizado por meio de práticas já se demonstrou eficaz em outros estudos como o demonstrado por Leal et al 2014, onde através de uma experiência com a queima de uma vela foi transmitido o conhecimento sobre cinética química, do mesmo modo a temática do projeto demonstrou a diferença de densidade entre a água quente e a água gelada por meio da prática.

Nesse caso utilizando apenas corante alimentício azul e vermelho, dois copos, uma divisória plástica e água, onde a água gelada tingida de azul foi colocada no copo inferior, em outro copo a água quente tingida de vermelho, foi tampada com a divisória plástica e sobreposta sobre o copo com água gelada, ao retirar a divisória foi possível observar que não houve a mistura das águas, demonstrando a influencia da temperatura na água. Tal experimento permite abordar outras questões influenciadas pela temperatura da água que vão além da química, como as correntes marítimas e sua importância na regulação do clima global, levando a outros questionamentos, como se a água de temperatura fria se desloca para fundo, como temos lugares em que a agua gelada está na superfície, como em Cabo frio no Rio de Janeiro? A resposta da questão envolve outros saberes como o fenômeno da ressurgência e outros. Esse levantamento de novas questões, novos pensamento permite conectar diversas dimensões 
de disciplinas e conteúdos, com assuntos que estão no dia a dia da sociedade.

Figura 11: Experiência densidade da água.

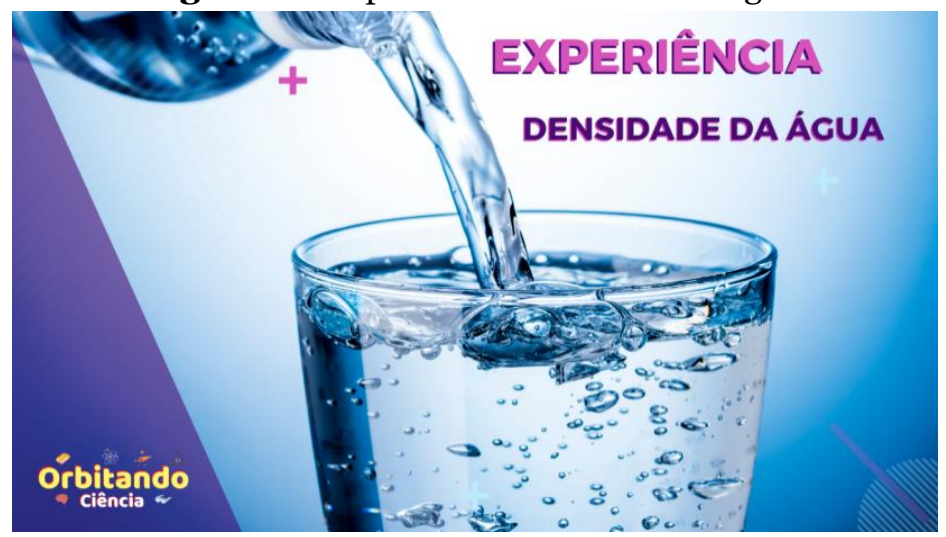

Fonte: RIBEIRO, 2020

Questões que envolvem perguntas como: por que é mais fácil boiar na água do mar? Ou porque não é possível mergulhar no mar morto? Responde fenômenos naturais que podem ser explicados pela química, tais explicações podem ser demonstradas por pequenas experiências fáceis de se reproduzir com utensílios domésticos, como exemplo no projeto orbitando ciência foi realizada uma experiência de se colocar um ovo em um copo com água da torneira e outro copo com agua acrescida de sal e colocar o ovo também, o resultado obtido foi que no copo de água com sal o ovo passou a boiar, diferentemente do copo de água sem sal, no qual o ovo afundou, nesse contexto foi possível observar o efeito da salinidade da água e 
como ela afeta a densidade da água, sendo que quanto maior a salinidade maior a densidade da água, como acontece no mar morto (Figura 12).

Figura 12: Efeito do sal na densidade da água.

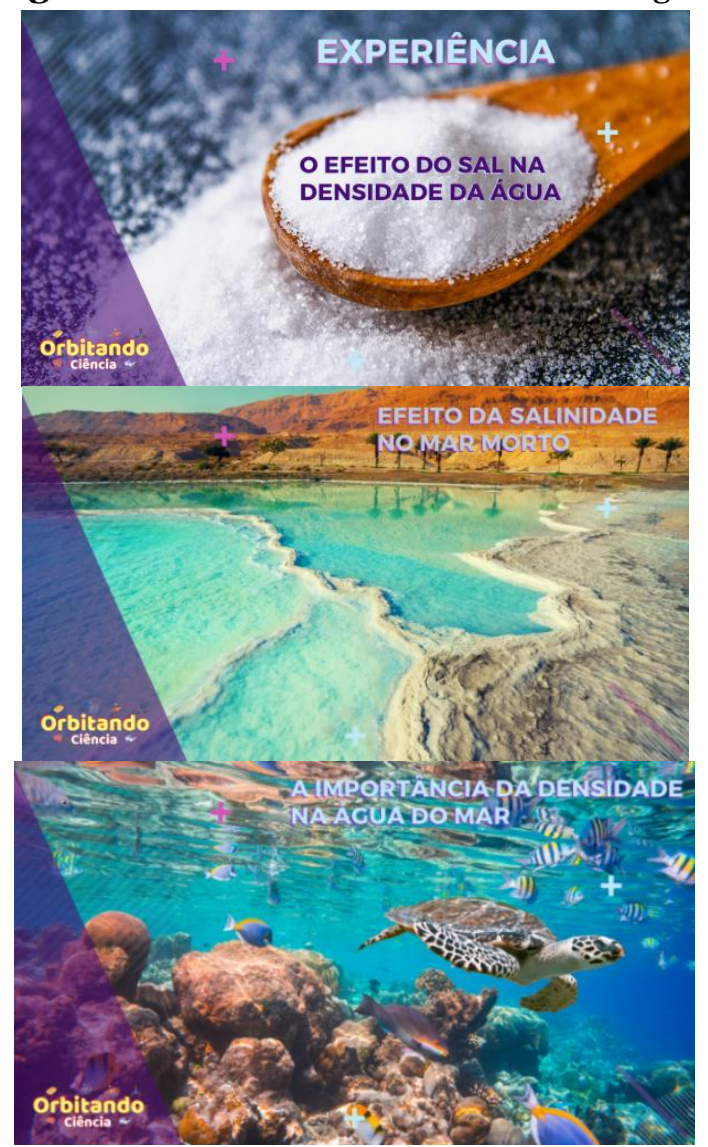

Fonte: RIBEIRO, 2020 
A abordagem de assuntos científicos no ensino da ciência se demonstra ser importante para a produção de alunos com pensamentos críticos, além de saber como escrever e para quem escrever. Como argumentado por Oliveira et al (2014), que aponta a necessidade dos alunos de saber "fazer ciência", vários estudos levantam maneiras de inserir a abordagem cientifica no ensino de ciência, para que o aluno tenha a capacidade de fomentar a ciência, e posteriormente divulgá-la, como a atividade inserção do peer review no ensino superior de Química.

\section{Abrangência do público-alvo}

Para a divulgação cientifica nos tempos atuais, torna-se necessária a utilização de ferramentas virtuais, como forma de se aproximar do publico alvo, a diversidade de ferramentas proporciona uma abordagem mais completa, pois além de conseguir levar o conteúdo a lugares mais distantes, possibilitando a troca de aprendizagens entre culturas e países diferentes, as ferramentas virtuais também podem ser objetos de ensino como demonstrado por Giordan e Goys (2009), que abordou a evolução das ferramentas virtuais de 1994 a 2005, que permitem integrar representações de diferentes níveis como macroscópio, nanoscópio e simbólico, combinando varias dimensões de conhecimento da química por meio de representações. 
A união de atividades de abordagem cientifica e ferramentas virtuais com abordagem de fatos e acontecimentos do cotidiano permite contextualizar a percepção de cada aluno com os saberes de química, podendo gerar um maior envolvimento e engajamento dos alunos nas disciplinas e posteriormente levar o saber para a sociedade. O projeto orbitando Ciência procura utilizar essa união de conhecimentos e ferramentas para indivíduos de diferentes idades, abrangendo o ensino fora da sala de aula. Foi possível observar a abrangência do público-alvo na figura 13, onde foi encontrado seguidores desde a faixa etária escolar (13-17 anos) até adultos de 65 anos ou mais.

Figura 13: Métricas do perfil de seguidores do projeto orbitando ciência no Instagram, por faixa etária e sexo.

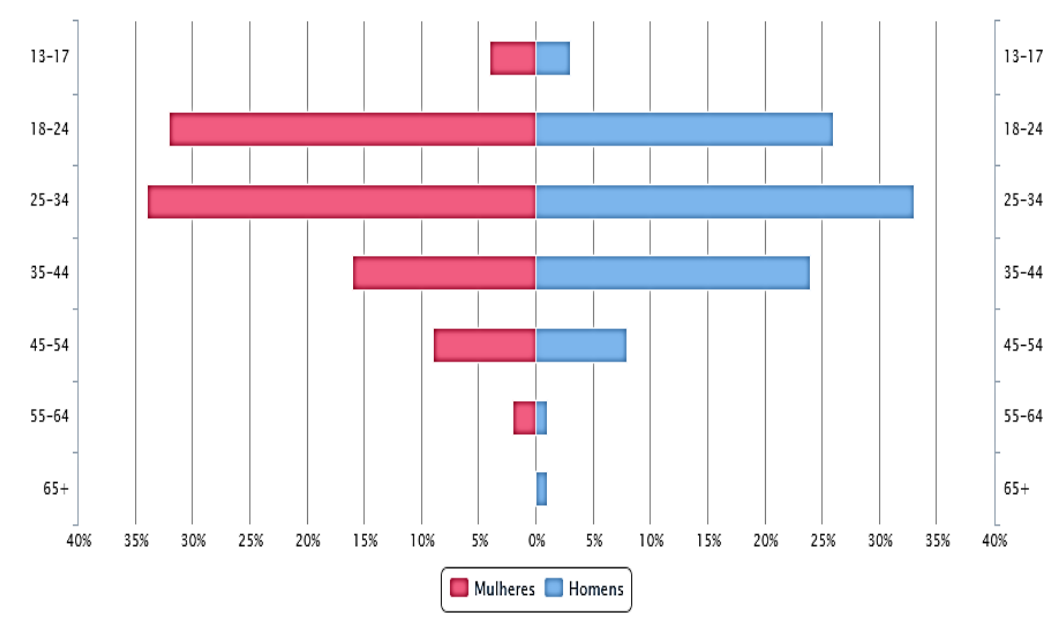

Fonte: RIBEIRO, 2020 
Como exposto por Fernandes et al (2015) o grande desafio é conceber uma metodologia de ensino que rompa a linearidade do ensino, utilizando os meios tecnológicos como ferramenta de ensino e apoio ao professor em sala de aula, e posteriormente levar isso a toda população de uma forma geral, diminuindo a barreira entre sala de aula e sociedade, podendo ser replicado em outras matérias que também poderiam abordar assunto do cotidiano como o ensino da física. (Araújo et al,2012)

\section{Conclusão}

O projetou conseguiu relacionar o conteúdo científico proporcionado por meio de artigos ao contexto da química no cotidiano de uma forma mais objetiva e clara, bem como atingir um público abrangente com uma faixa etária de 13 a 65 anos de idade, atendendo ao objetivo de divulgar a ciência diferente públicos dialogando com a sociedade.

O projeto abordou diversas esferas do conhecimento correlacionadas à química, abordando conteúdos simples e temas atuais, ressaltando a importância da ciência para o desenvolvimento da sociedade e do papel do indivíduo como agente transformador, permitindo contextualizar a química em um conjunto de saberes para uma percepção dos processos químicos envolvidos nos fenômenos do dia a dia. 
Os vídeos e redes sociais vêm se tornando meio de pesquisa e esclarecimentos de diversos contextos da sociedade, porém carece de conteúdos de qualidade e baseado em artigos científicos. As plataformas poderiam ser mais bem exploradas para disseminação de divulgação científica e aprendizado, envolvendo abordagens mais lúdicas e assuntos do cotidiano, trazendo a atenção da sociedade para a ciência e sua importância, permitindo uma nova percepção de mundo e em longo prazo uma nova cultura e pensamento ambiental e social. A divulgação científica deveria começar nas universidades, depois ser fomentado sua divulgação para sociedade.

\section{Referências}

ARAÚJO, S.; VEIT, E. A.; MOREIRA, M. A. Modelos computacionais no ensino-aprendizagem de física: um referencial de trabalho. Investigações em Ensino de Ciências, v. 17, n. 2, 2012.

FAPESP. Pesquisadores da empresa paulista Nanox, apoiada pelo Programa FAPESP Pesquisa Inovativa em Pequenas Empresas (PIPE), desenvolveram um tecido com micropartículas de prata na superficie que demonstrou ser capaz de inativar o coronavírus SARS-CoV-2. Disponível em: $<$ https://agencia.fapesp.br/empresa-paulista-desenvolvetecido-capaz-de-eliminar-o-novo-coronavirus-porcontato/33414/>. Acesso: 10/09/2020

FERNANDES, G. W. R.; RODRIGUES, A. M.; FERRREIRA, C. A. Virtual thematic modules: an educational proposal for sci- 
ence education and the use of ICT. Caderno Brasileiro de Ensino de Física, v. 32, n. 3, p. 934-962, 2015.

FERREIRA, L. N. de A.; IMASATO, H.; QUEIROZ, S. L. Textos de divulgação científica no ensino superior de química: aplicação em uma disciplina de Química Estrutural. Educ. quím., v.23, n.1, p. 49-54, 2012.

GIORDAN, M.; GOIS, J. Entornos virtuales de aprendizaje en química: una revisión de la literatura. Educación Química, p. 301-313, 2009.

GREAVES, J. S.; RICHARDS, M. A. S.; BAINS, W. et al. Gás fosfina nas nuvens de Vênus. Nat Astron (2020). https://doi.org/10.1038/s41550-020-1174-4

IBGE- Instituto Brasileiro de geografia e estatística. Pesquisa Nacional por Amostra de Domicílios Contínua, 2018. Disponível

em:

https://biblioteca.ibge.gov.br/visualizacao/livros/liv101631_in formativo.pdf. Acesso: 12/09/2020.

LEAL, R. C.; MONTEIRO, E. A. de S.; NASCIMENTO, T. L. de A. B.; MOITA NETO, J. M. Explorando a cinética química através da queima de uma vela. Educ. quím., v.25, n.2, p.9396, 2014.

LITWIN, E. Tecnologías educativas em tiempos de Internet. Amorrortu editores. Buenos Aires, 2005.

MANSILLA, D. S.; MUSCIA, G. C.; UGLIAROLO, E. A. Campus Virtual y Facebook en el ámbito universitario. Enemigos o aliados en los procesos de enseñanza y aprendizaje. Educ. quím., v.24,n.2, p.255-259, 2013. 
MARTINI, A.; BIONDI, D.; BATISTA, A. C.; ZAMPRONI, K. Valores extremos do índice de conforto térmico nas ruas de Curitiba- PR: Comparação entre ambientes arborizados e sem arborização. RevsBAU, v.8,n.3,p52-62,2013.

MIRANDA, J. L. de; SILVA, F. G. de O. da ; ALMEIDA, C. D. de; GERPE, R. O Antropoceno, a Educação Ambiental e o Ensino de Química. Rev. Virtual Quim. V.10, n.6, p. 1990-2004, 2019.

OLIVEIRA, J. R. S. de; PORTO, A. L. M.; QUEIROZ, S. L. Peer review no ensino superior de química: atividade didática para a apropriação do discurso da ciência. Educ. quím., v.25, n.1, p.35-41, 2014.

PALAMIDESSI, M. I.; GOROSTIAGA, J. M.; SUASNÁBAR, C. El desarrollo de la investigación educativa y sus vinculaciones con el gobierno de la educación en América Latina. Perfiles Educativos, v.36, n. 143, p49-66,2014

RIBEIRO, P. C.; NASCIMENTO, L. F. C.; ALMEIDA, A. A.; TARGA, M. S.; CESAR, A. C. G. Fine particulate matter and ischemic heart diseases in relation to sex. An ecological time series study, Sao Paulo Med J, v.137, n 1, p.60-5, 2019.

RIBEIRO, P. C. Orbitando Ciência. Instagram, 2020. Disponível em: <https://www.instagram.com/orbitandociencia $>$. Acesso: 08/09/2020

SOUZA, J. I. R.; LEITE, B. S. Utilização das Séries de TV no Ensino de Química. Rev. Virtual Quim., v.10, n.4, p.749-766, 2018.

VENTURA, B.; NEVES, R. L.; RIBEIRO, V. G. P.; VALE, M. R.; GUEDES, I.; MAZZETTO, S. E. Teatro no Ensino de Química: 
Relato de Experiência. Rev. Virtual Quim., v.10, n.4, p. 824840, 2018.

VARGAS, H.; SÁNCHEZ, J.; JARA, C. A.; CANDELAS,F., REINOSO, O.; DÍEZ, J. L. Docencia en Automática: Aplicación de las TIC a la realización de actividades prácticas através de Internet. RIAI, v.7, n.1, p.35-45, 2010. 